\title{
Inter-annual variations in wave spectral characteristics at a location off the central west coast of India
}

\author{
V. Sanil Kumar and M. Anjali Nair \\ Ocean Engineering, CSIR-National Institute of Oceanography (Council of Scientific \& Industrial Research) Dona Paula, \\ Goa 403 004, India \\ Correspondence to: V. Sanil Kumar (sanil@ nio.org)
}

Received: 16 October 2014 - Revised: 22 December 2014 - Accepted: 11 January 2015 - Published: 3 February 2015

\begin{abstract}
The inter-annual variations in wave spectrum are examined based on the wave data measured at $9 \mathrm{~m}$ water depth off the central west coast of India from 2009 to 2012 using a wave rider buoy. The temporal variation of the spectral energy density over a calendar year indicates similar variation in all the four years studied. The inter-annual variations in wave spectrum are observed in all months with larger variations during January to February, May and October to November due to the changes in wind-sea. The seasonal average wave spectrum during the monsoon (June-September) is single-peaked and the swell component is high in 2011 compared to other years. The annual averaged wave spectrum had higher peak energy during 2011 due to the higher spectral energy present during the monsoon period. During the non-monsoon period, two peaks are predominantly observed in the wave spectra; with the average peak at $0.07 \mathrm{~Hz}$ corresponding to the swells from the Indian Ocean and another at $0.17 \mathrm{~Hz}$ due to the local wind field.
\end{abstract}

Keywords. History of geophysics (ocean sciences)

\section{Introduction}

Surface waves generated by winds are of importance for scientific and practical use. The sea state is often described in the frequency domain by a wave spectrum. The wave spectrum describes how the wave energy is distributed over a range of frequencies and is used to identify the different wave systems present at the measurement location (Soares, 1991; Hanson and Phillips, 2001; Cuchiara et al., 2009). The spectral description of the sea states is an important input for the design of marine structures. Several studies have shown that combined wind-wave and swell systems can occur both in the open ocean and in coastal areas (Soares, 1991). The coexistence of wind-sea and swell can significantly affect seakeeping safety, offshore structure designs, small boat operations and ship passages over harbour entrances, and surf forecasting (Earle, 1984). The monsoons of the Indian Ocean are an example of particularly strong ocean-atmosphere interaction over basin scales and the Arabian Sea plays an important role in modulating the monsoon over the Indian Ocean. The large-scale wind field in the northern Indian Ocean reverses between boreal summer and winter, leading to changes in the waves. The earlier studies indicate that the wave spectra in the eastern Arabian Sea are bimodal due to the presence of wind-seas and swells (Baba et al., 1989; Kumar et al., 2000, 2003, 2014; Kumar and Kumar, 2008; Vethamony et al., 2011). Some studies based on satellite derived data have indicated that globally the mean wind speed and the wave height are increasing (Young et al., 2011). Hence, it is important to know the inter-annual variations in wave spectra based on the measured data.

The inter-annual variations in wave characteristics are generally studied by comparing the bulk wave parameters i.e. significant wave height, mean wave period, peak wave period and mean wave direction (Carter and Draper, 1988; Caires and Swail, 2004; Sajiv et al., 2012; Vanem and Walker, 2013; Shanas and Sanil Kumar, 2014). The earlier studies indicated that spatially the seasonal average bulk wave parameters (wave height and period) did not vary significantly in the eastern Arabian Sea (Glejin et al., 2012; Kumar et al., 2012; Anoop et al., 2014).

Since the inter-annual variations in wave spectral characteristics are not known off the central west coast of India, a study is carried out for the period of 2009-2012. The location selected for the study is at $9 \mathrm{~m}$ water depth off Honnavar, 


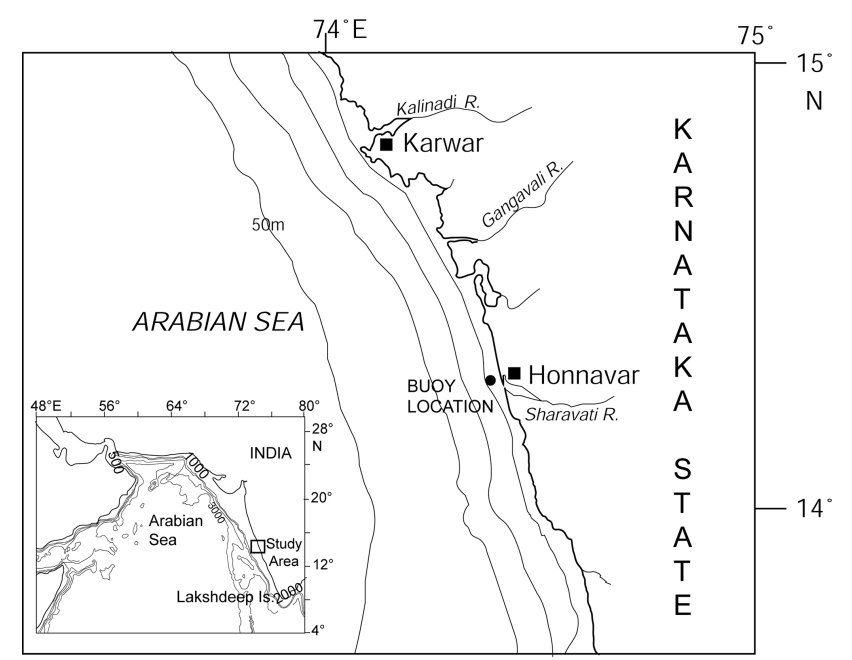

Figure 1. Map showing the study location.

where the measured wave data is available (Fig. 1). The geographical co-ordinates of the location are $14.3042^{\circ} \mathrm{N}$; $74.3907^{\circ} \mathrm{E}$ and the location is $2.5 \mathrm{~km}$ off the west coast of the Indian mainland. The objective of the study is to investigate the characteristics of wind wave spectra and thus, to have a better understanding of the nature of the waves occurring in the region. The inter-annual and seasonal variations in the bulk wave parameters of the study location from March 2008 to March 2011 were studied by Sajiv et al. (2012) and the wave spectral characteristics during 2011 at this location were reported by Kumar et al. (2014). Anoop et al. (2014) studied the temporal variations of the bulk wave parameters during 2011 and 2012 at locations situated 80 and $350 \mathrm{~km}$ north of the present study location.

\section{Materials and methods}

Wave data measured by the Datawell directional wave rider buoy is used in the study. The data recorded continuously at $1.28 \mathrm{~Hz}$ and the data of $30 \mathrm{~min}$ duration are processed as one record. The details of the data collection and analysis were presented in Kumar et al. (2014). The wave spectrum is computed from the measured time series of the heave motion of the buoy using fast Fourier transform. The frequency resolution is $0.005 \mathrm{~Hz}$ for frequencies less than $0.1 \mathrm{~Hz}$, and $0.01 \mathrm{~Hz}$ otherwise. Significant wave height $\left(H_{m 0}\right)$ is estimated from the wave spectrum. Mean wave direction is estimated from the measured time series of heave and the two translational (north-south and east-west) motions of the buoy based on circular moments (Kuik et al., 1988). Measurements are made in Coordinated Universal Time (UTC) and the time referred in the paper is UTC. The wind data used in the study is the reanalysed zonal and meridional components of the wind speed at $10 \mathrm{~m}$ height at $6 \mathrm{~h}$ intervals from NCEP/NCAR (Kalnay et al., 1996) on an approximately $2^{\circ}$ grid. These

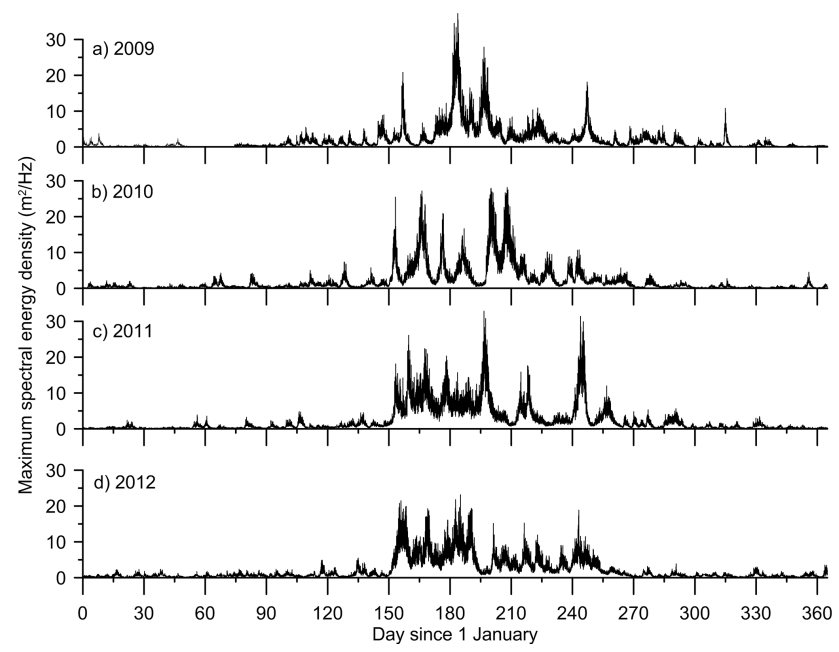

Figure 2. Time series plot of maximum spectral energy density in a calendar year during 2009-2012.

data were provided by the NOAA-CIRES Climate Diagnostics Center, Boulder, Colorado at http://www.cdc.noaa.gov/.

The frequency bins over which the wave spectrum was estimated every half hour is the same in all years. Hence, from the half-hourly wave spectrum, the monthly and seasonally averaged wave spectrum is computed by taking the average of the spectral energy density at the respective frequencies over the specified time. Similarly, the monthly and seasonally averaged mean wave direction at different frequencies is also estimated.

\section{Results and discussions}

\subsection{Temporal variation in wave spectra}

The time series plot of the maximum spectral energy density over a calendar year indicates that the spectral energy density is high $\left(5-37 \mathrm{~m}^{2} \mathrm{~Hz}^{-1}\right)$ during the monsoon period (June-September) due to the persistence of strong southwest (SW) winds in the Arabian Sea as a result of the SW monsoon (Fig. 2). The seasonally averaged spectral energy density for the $\mathrm{SW}$ monsoon period is $4.1 \mathrm{~m}^{2} \mathrm{~Hz}^{-1}$ during 2009 , $4.8 \mathrm{~m}^{2} \mathrm{~Hz}^{-1}$ during 2010 and 2012 and is $5.5 \mathrm{~m}^{2} \mathrm{~Hz}^{-1}$ during 2011. The spectral energy density is relatively high during 2011 SW monsoon compared to other years. During the non-monsoon period, the maximum spectral energy density is less than $5 \mathrm{~m}^{2} \mathrm{~Hz}^{-1}$ with an average value of $0.6 \mathrm{~m}^{2} \mathrm{~Hz}^{-1}$. The annual average value of maximum spectral energy density is also high $\left(\sim 2.3 \mathrm{~m}^{2} \mathrm{~Hz}^{-1}\right)$ during 2011 compared to 2009, 2010 and $2012\left(\sim 2.0 \mathrm{~m}^{2} \mathrm{~Hz}^{-1}\right)$. The annual maximum value of maximum spectral energy density is $37,33,28.1$ and $23.2 \mathrm{~m}^{2} \mathrm{~Hz}^{-1}$ in 2009, 2011, 2010 and 2012.

In order to understand the evolution of spectral components over time, the contour plots of wave spectral energy 


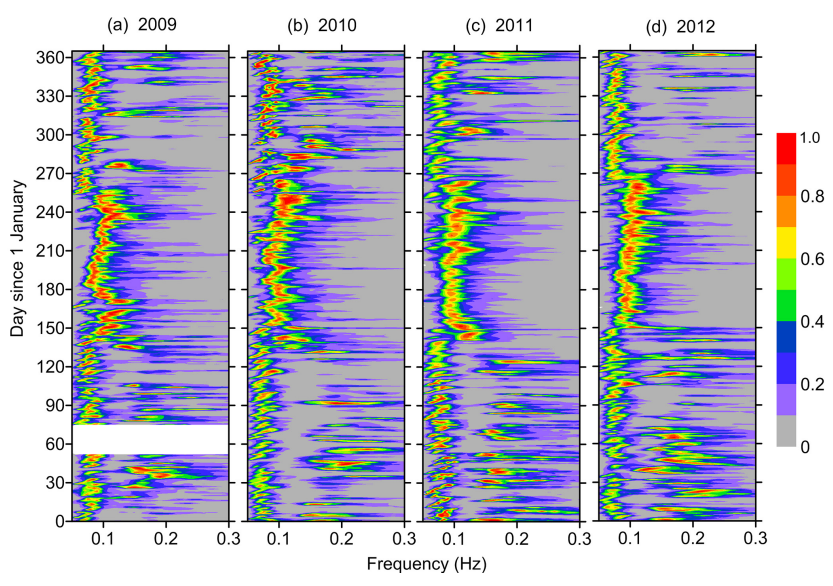

Figure 3. Temporal variation in normalised wave spectral energy density during 2009-2012. The white patch indicates the gap in the data.

density in the frequency-time domain are drawn. The frequency band where most wave energy concentrates is also of importance to a designer, to keep the natural frequency of the structure away from this frequency band to avoid resonance phenomenon. The temporal variations of the normalised spectral energy density with frequency (unit spectrum) for the years 2009, 2010, 2011 and 2012 are presented in Fig. 3. The spectral energy density at each frequency is divided with the maximum spectral energy density of the respective spectrum to obtain the normalised spectral energy density. In all the years, from June to August (Julian day 151 to 243), the wave spectra is narrow-banded with wave spectral energy density predominantly between frequencies 0.07 and $0.12 \mathrm{~Hz}$ (14 and $8 \mathrm{~s}$ ) and in September, the wave spectral energy density is predominantly between 0.09 and $0.14 \mathrm{~Hz}(11$ and $7 \mathrm{~s})$. Barring the SW monsoon period, the wave spectra are broad-banded with the presence of windseas and swells. From January to April, the spectral energy peak is predominantly in the low frequency side due to the presence of long-period swells and occasionally the predominance of wind-sea is also observed. The temporal variation in spectral energy density over the annual period is similar during all four years studied.

The direction of different waves in a wave train can be identified from the plot of wave direction in the frequencytime domain. From January to May and from October to December, the low frequency $(<0.12 \mathrm{~Hz})$ waves are from 210 to $240^{\circ}$ (Fig. 4). From March to May and in October, the high frequency waves are predominantly from 270 to $300^{\circ}$, whereas from November to February, the high frequency waves are from a direction more than $300^{\circ}$ due to the prevailing NW wind in the Arabian Sea (Fig. 5). During the SW monsoon period, most of the waves are from 240 to $270^{\circ}$ except the waves with frequency less than $0.08 \mathrm{~Hz}$, which are from 210 to $240^{\circ}$. In July-August 2009, high frequency waves from 270 to $300^{\circ}$ are also observed. Anoop et

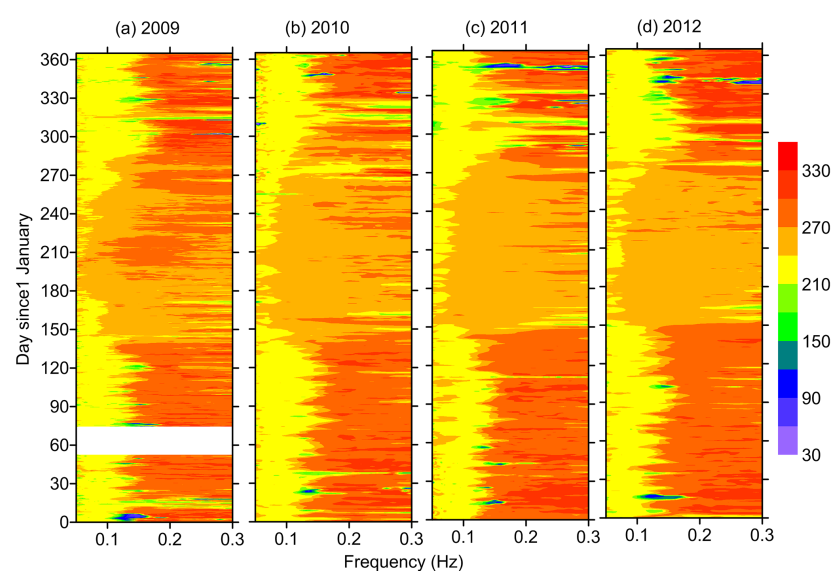

Figure 4. Temporal variation in mean wave direction during 2009_ 2012. The contour levels are the mean wave direction in degrees. The white patch indicates the gap in the data.

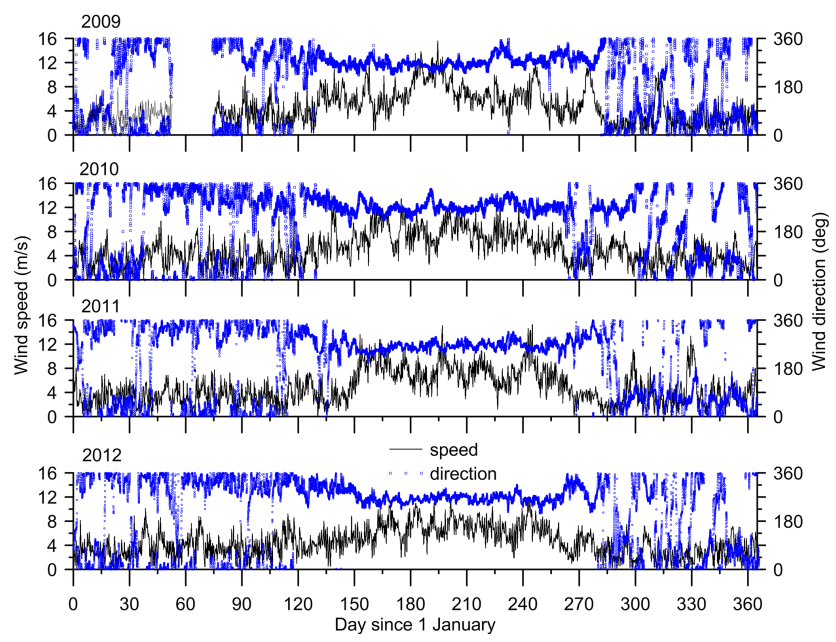

Figure 5. Time series plot of wind speed and direction at $12.5^{\circ} \mathrm{N}$ $72.5^{\circ}$ E during 2009, 2010, 2011 and 2012.

al. (2014) observed that during the monsoon period, the wave characteristics are similar for the $270 \mathrm{~km}$ long stretch in the eastern Arabian Sea since the waves along this part are predominantly $(\sim 72 \%)$ swells. Figure 4 also indicates locally generated waves with low energy and high frequency from the southeast.

A typical directional wave spectrum during the nonmonsoon and monsoon period is presented in Fig. 6. Two well-defined peaks are observed during the non-monsoon period due to the presence of wind-seas (from $280-320^{\circ}$ ) and swells (from $210-240^{\circ}$ ) in the study area. These peaks represent the wind-seas generated close to the coast by local winds and long-period waves originating in the Southern Indian Ocean, far away from the coast (Glejin et al., 2013; Kumar et al., 2014). During the monsoon period, a mainly single-peak wave spectrum is observed with waves from $240-270^{\circ}$. 


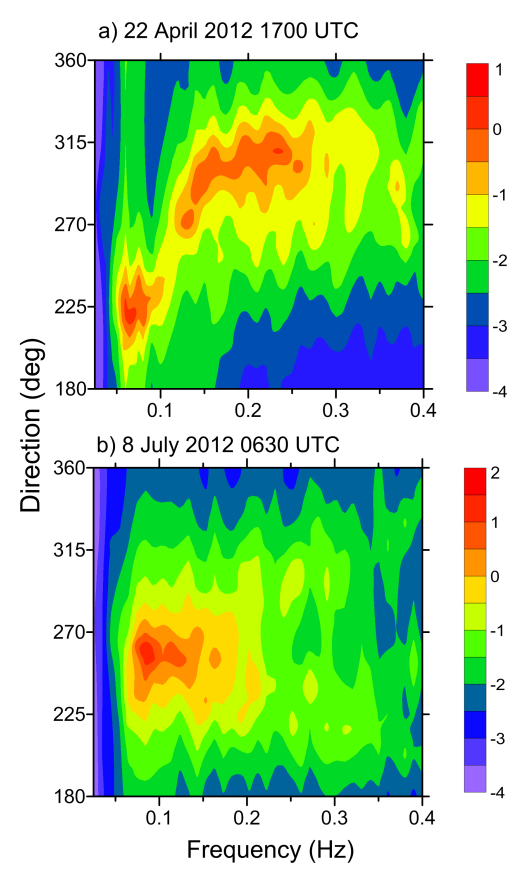

Figure 6. Typical directional wave spectrum during the (a) nonmonsoon and (b) monsoon period. Contours presented are the spectral energy density $\left(\mathrm{m}^{2} \mathrm{~Hz}^{-1} \mathrm{deg}^{-1}\right)$ in logarithmic scale.

\subsection{Inter-annual variations in monthly and seasonally averaged wave spectra}

The monthly averaged wave spectrum is computed to study the inter-annual variations of spectral energy density for different months during 2009-2012. The main spectral characteristic deduced from the monthly average spectrum is the presence of large amounts of energy in the swell frequency and less energy in the wind-sea frequency. Monthly averaged wave spectra are single-peaked during the SW monsoon period (June-September) in all years and double-peaked during the rest of the year (Fig. 7). Swells from the south Indian Ocean and the locally generated wind-seas are responsible for the double-peaked wave energy spectrum in the eastern Arabian Sea (Kumar et al., 2014). From January to March, the wind-sea component is high in 2012 compared to 2010 and 2011 due to the relatively stronger winds present in the study area (Fig. 5). The variation in monthly averaged wave spectrum in June for different years is due to the low wave activity in 2009 resulting from the delayed monsoon compared to other years. During 2008-2010, Sajiv et al. (2012) also noted large variations in monthly average value of $H_{m 0}$ in June. The high wind-sea peak during November 2009 is due to the cyclonic storm Phyan which passed off the west coast of India. The study shows that the inter-annual variations in wave spectrum are observed in all months with larger changes during January-February, May and OctoberNovember. Inter-annual changes observed in the wave spectrum are due to the changes in the local wind and the swells
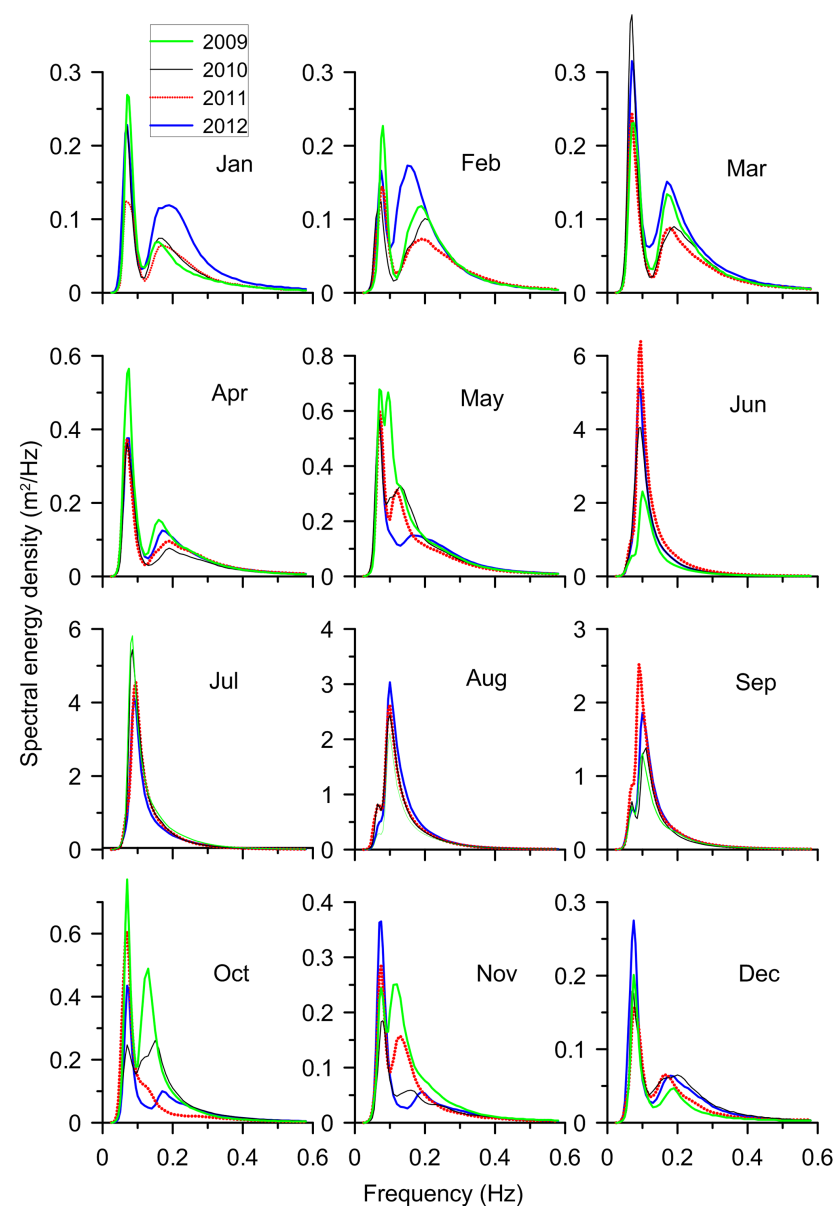

Figure 7. Inter-annual variations in monthly averaged wave spectrum during 2009-2012.

from the Southern Ocean and the variations in monsoon intensity. Even though the monthly average peak frequency of the swell is the same during all years, there is variation in the monthly average peak frequency of the wind-sea.

Since there are variations in the monthly averaged wave spectrum for different years, the variation in the average wave spectrum during different seasons is examined. During the pre-monsoon period (February-May), the swell component in all years is same except in 2009 and also there is variation in the wind-sea component (Fig. 8a). The windsea component is high in 2009 and 2012 compared to other two years. During the monsoon, the wave spectrum is singlepeaked and the swell component is higher in 2011 compared to the other three years (Fig. 8b). In the post-monsoon period (October-January), the swell component is low during 2010 but high during 2009 (Fig. 8c). The wind-sea component is also high during 2009 due to the "Phyan" cyclonic storm. The shape of the annual averaged wave spectrum is similar for all four years, with higher peak energy during 2011, due to the higher spectral energy present during the monsoon period (Fig. 8d). 


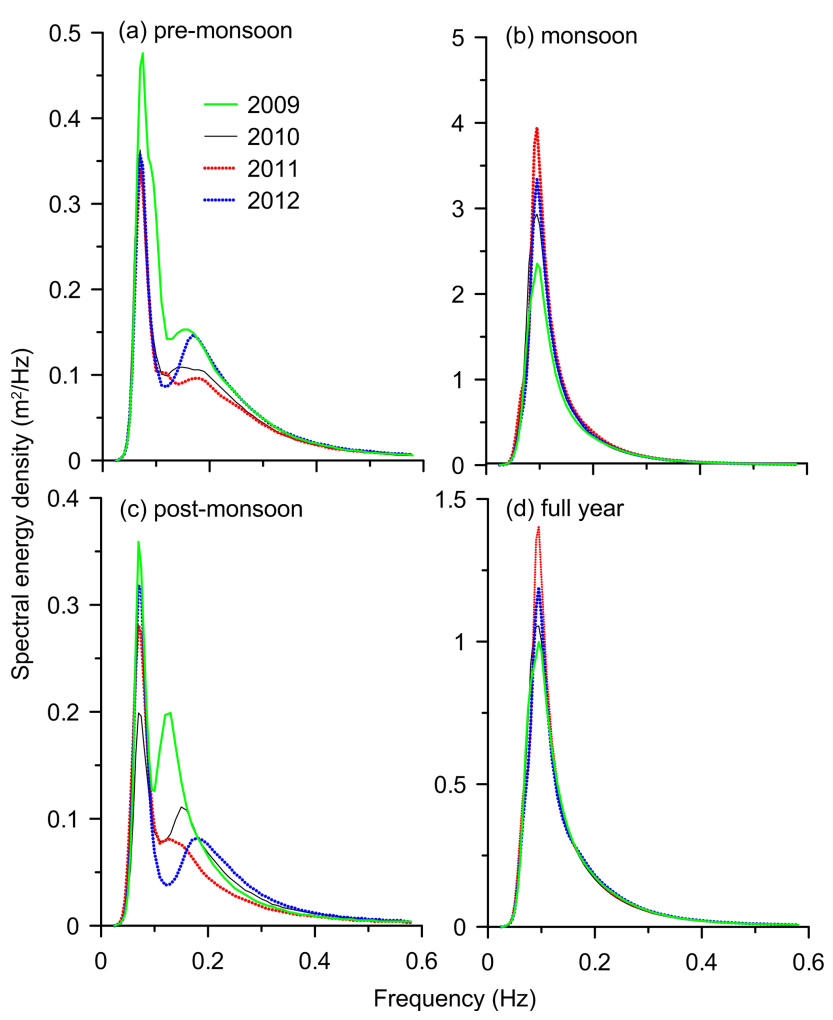

Figure 8. Wave spectra averaged over (a) pre-monsoon, (b) monsoon, (c) post-monsoon and (d) full year, for different years.

During 2009-2012, the maximum wave height recorded is $6.8 \mathrm{~m}$, on 4 July 2009 at 01:30 UTC. The tide at the same time was around $0.8 \mathrm{~m}$. The ratio of wave height to water depth is 0.69 , which is less than the breaking criteria of 0.78 (USACE, 1984). Hence, no waves were breaking regardless of the wave height to depth ratio, but during high wind conditions some waves were probably breaking, affecting the buoy measurements locally (Pascal et al., 2011). However, it was not possible to correct wave height measurements due to whitecapping.

The waves with $H_{m 0}>2 \mathrm{~m}$ are observed for 10 to $15 \%$ of the time in a year and are during the SW monsoon period. The spectral shape of these waves is required to design the marine structures. The annual average spectrum of waves with $H_{m 0}$ more than $2 \mathrm{~m}$ is similar for the four years, with the peak frequency around $0.09 \mathrm{~Hz}$ (Fig. 9a). Kumar and Kumar (2008) represented the shallow water wave spectrum of high waves $\left(H_{m 0}>2 \mathrm{~m}\right)$ with a JONSWAP spectrum (Hasselman et al., 1973) with modified parameters $(\alpha=0.0027$ and $\gamma=1.63$ ). Since these high wave spectra along the eastern Arabian Sea are mainly swells, and it is a narrow spectrum, the JONSWAP spectrum with appropriate peak enhancement parameter $(\gamma)$ can represent the swell (Goda, 1983). The study shows that the spectrum of high waves $\left(H_{m 0}>2 \mathrm{~m}\right)$ can be represented with a JONSWAP spectrum (Fig. 10). A fitted JONSWAP spectrum is obtained by select-

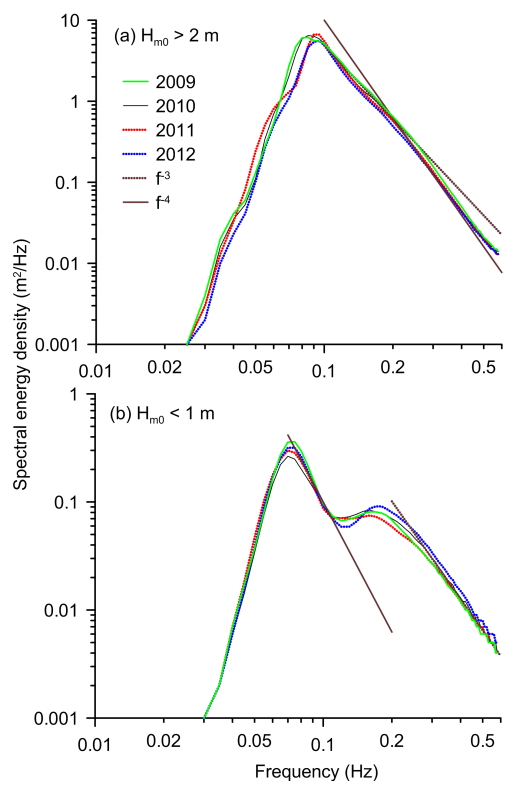

Figure 9. Annual averaged wave spectra for different years for waves with significant wave height (a) more than $2 \mathrm{~m}$ and (b) less than $1 \mathrm{~m}$.

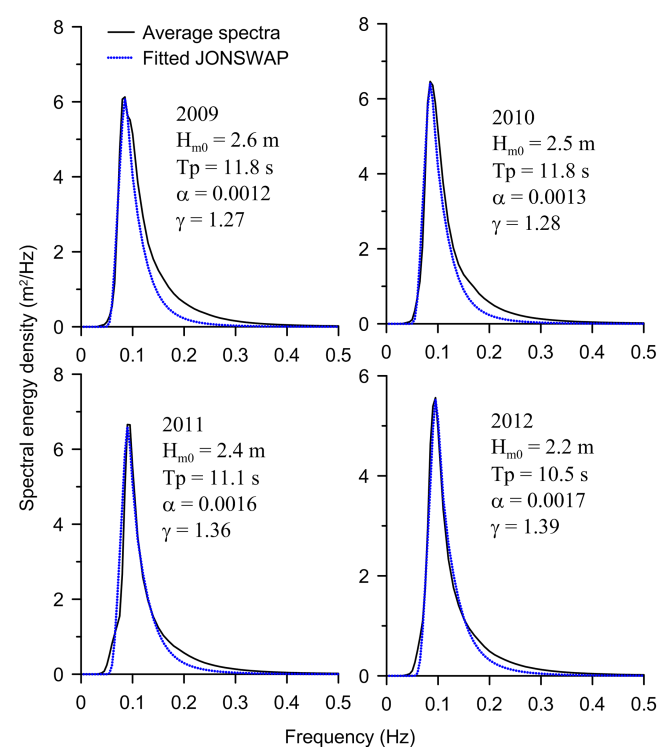

Figure 10. Averaged wave spectra for waves with significant wave height more than $2 \mathrm{~m}$ and the fitted JONSWAP spectra for different years.

ing the parameter $\alpha$ (Phillips constant) and $\gamma$ of the JONSWAP spectrum such that the peak of the spectrum agrees. For high waves $\left(H_{m 0}>2 \mathrm{~m}\right), \alpha$ range from 0.0012 to 0.0017 and $\gamma$ from 1.27 to 1.39 for different years. The estimated values of the JONSWAP parameters are less than the generally recommended values of 0.0081 and 3.3, respectively. For frequencies above $0.13 \mathrm{~Hz}$, the fitted JONSWAP spectra deviate from the measured data. In the JONSWAP spec- 

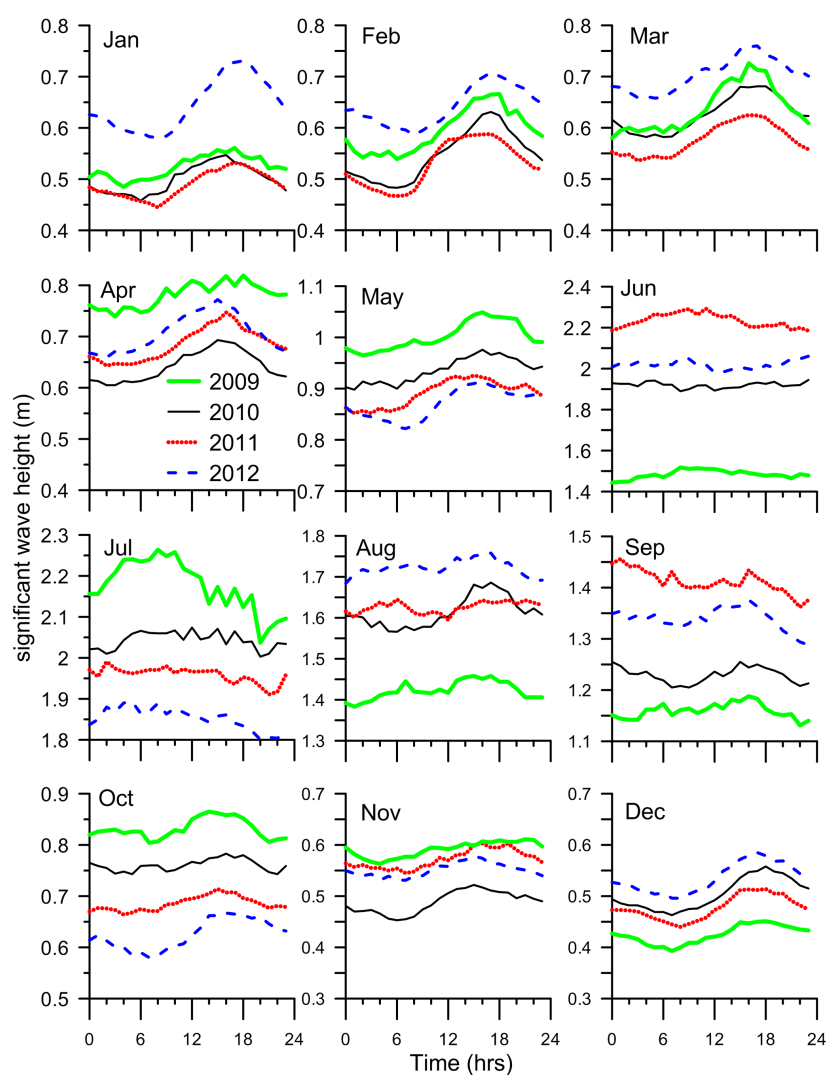

Figure 11. Variation in half-hourly significant wave height averaged monthly with time.

trum, the rate of energy decay for the high frequency part is inversely proportional to frequency to the fifth power. The high frequency tail that best describes the spectral decay is still subject to debate, although in many studies there is clear evidence that its value lies between -3.5 and -5 (Donelan et al., 1985; Young and Verhagen, 1996).

For the study area, the high frequency part of the spectra of high waves $\left(H_{m 0}>2 \mathrm{~m}\right)$ is between the curves proportional to $f^{-4}$ and $f^{-3}$ (where $f$ is the frequency). For frequencies from 0.1 to $0.2 \mathrm{~Hz}$, the high frequency part is close to $f^{-3}$ and for frequencies from 0.2 to $0.4 \mathrm{~Hz}$, the high frequency part is close to $f^{-4}$ (Fig. 9a). Young and Verhagen (1996) found that the exponent of the spectral curve in the high-frequency region is approximately -5 in deep water and around -3 in finite depth. The waves with $H_{m 0}<1 \mathrm{~m}$ are observed for $65 \%$ of the time in a year and are mainly during the non-monsoon period. During the non-monsoon period, two peaks are predominantly observed; one at $0.07 \mathrm{~Hz}$ due to the swells from the Indian Ocean and another at $0.17 \mathrm{~Hz}$ due to the local wind field (Fig. 9b). During the non-monsoon period, the high frequency part of the wave spectrum beyond $0.2 \mathrm{~Hz}$ is proportional to $f^{-3}$. Whereas the decreasing of the high frequency part of the swell peak between 0.07 and $0.11 \mathrm{~Hz}$ is proportional to $f^{-4}$.
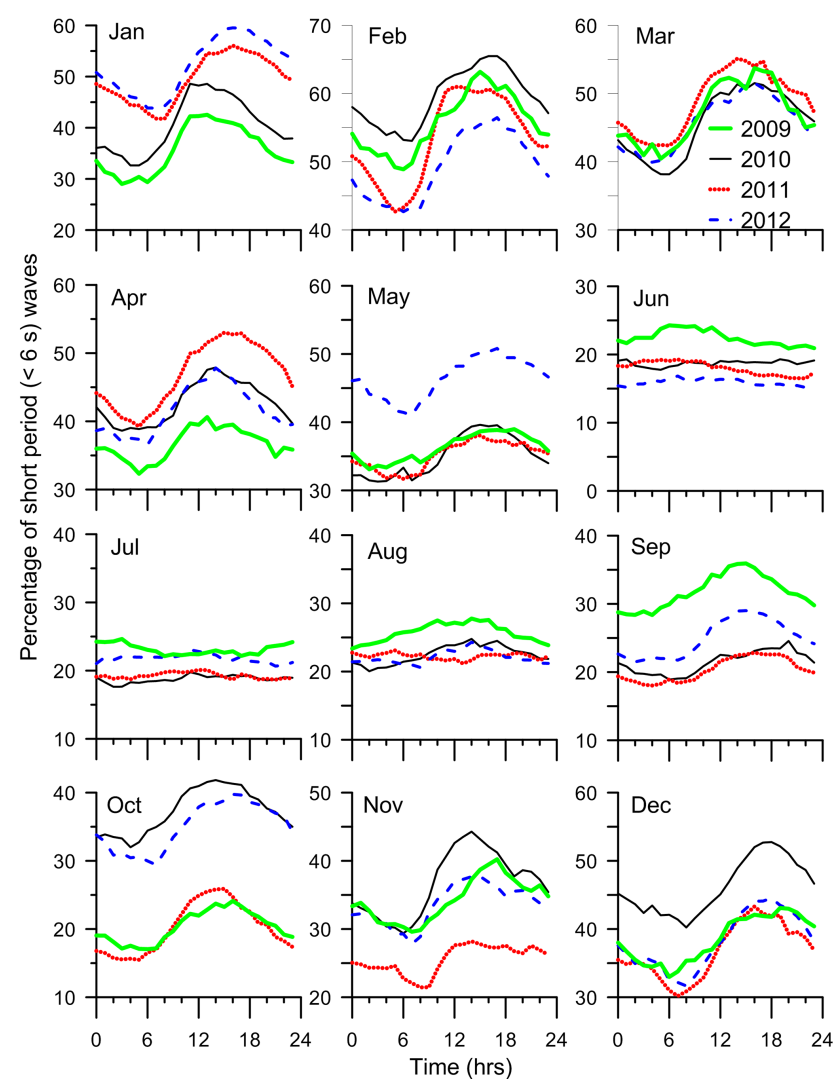

Figure 12. Variation in percentage of short period $(<6 s)$ waves in half-hourly records averaged monthly with time.

\subsection{Diurnal variation in wave spectral parameters}

Waves of amplitude $0.5 \mathrm{~m}<H_{m 0}<1 \mathrm{~m}$ are predominant and represent more than $42 \%$ of the annual wave climate while waves with $H_{m 0}>3 \mathrm{~m}$ represent about $1 \%$. Earlier studies along the eastern Arabian Sea indicate diurnal variation in wave parameters due to the influence of sea breeze (Neetu et al., 2006; Vethamony et al., 2011; Glejin et al., 2013; Kumar et al., 2014). The present study shows that the diurnal variation in the significant wave height are almost similar for all years (Fig. 11). The diurnal variation is high $(\sim 0.2 \mathrm{~m})$ during January-April and November-December, negligible $(<0.1 \mathrm{~m})$ during June and July (except in July 2009) due to the SW monsoon winds, and low $(\sim 0.1 \mathrm{~m})$ during rest of the year. The time during which the wave height reaches its maximum is not the same for different years. There is a difference of up to $2 \mathrm{~h}$ in the time at which the wave height reaches maximum during December and January (Fig. 11). Due to the sea breeze, the wave height reaches maximum during 15:00-18:00 UTC except during May. In May, the wave height reaches maximum at 13:00, 14:48, 16:12 and 16:12 UTC in 2011, 2012, 2009 and 2010. Aboobacker et al. (2014) reported that off the west coast of India in May 2005, the maximum wind-sea $H_{m 0}$ was observed between 18 

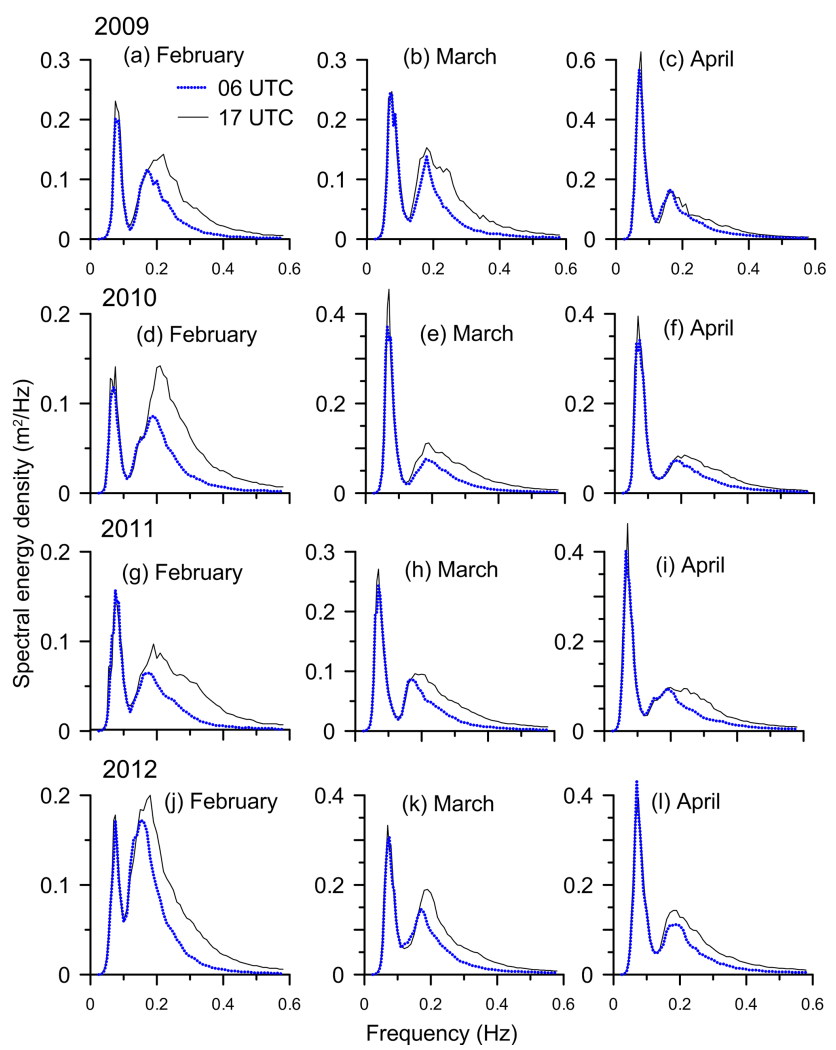

Figure 13. Monthly average wave spectrum during 06:00 and 17:00 UTC from February to April in (a-c) 2009, (d-f) 2010, (gi) 2011 and (j-l) 2012 .

and $21 \mathrm{~h}(12: 30$ and 15:30 UTC). The diurnal variation in the percentage of short-period waves $(T<6 \mathrm{~s}$; dominated by local seas) is examined since they are mainly locally generated waves. The percentage of short-period waves increased from 10 to $15 \%$ during January-April and November-December due to the sea breeze (Fig. 12). During June-August, diurnal variation in the percentage of short-period waves was less than 5 .

In order to know the change in the wave spectrum due to sea breeze, the monthly averaged wave spectra during 06:00 and 17:00 UTC are compared during the peak sea breeze period (February-April) for the years 2009-2012 (Fig. 13). The increase in the spectral energy of the wind-sea part is observed at 17:00 UTC compared to 06:00 UTC during February-April with a higher increase during February compared to other months. The increase is similar during all four years. The swell part of the spectrum is similar during 06:00 and 17:00 UTC in all the months studied. A slight increase in maximum spectral energy density of the swell is observed at 17:00 UTC in March 2010.

Due to the sea breeze, the mean wave direction changes from SW-W to NW-W during 06:00 to 17:00 UTC (Fig. 14). The swell direction is the same in each particular month for all four years.
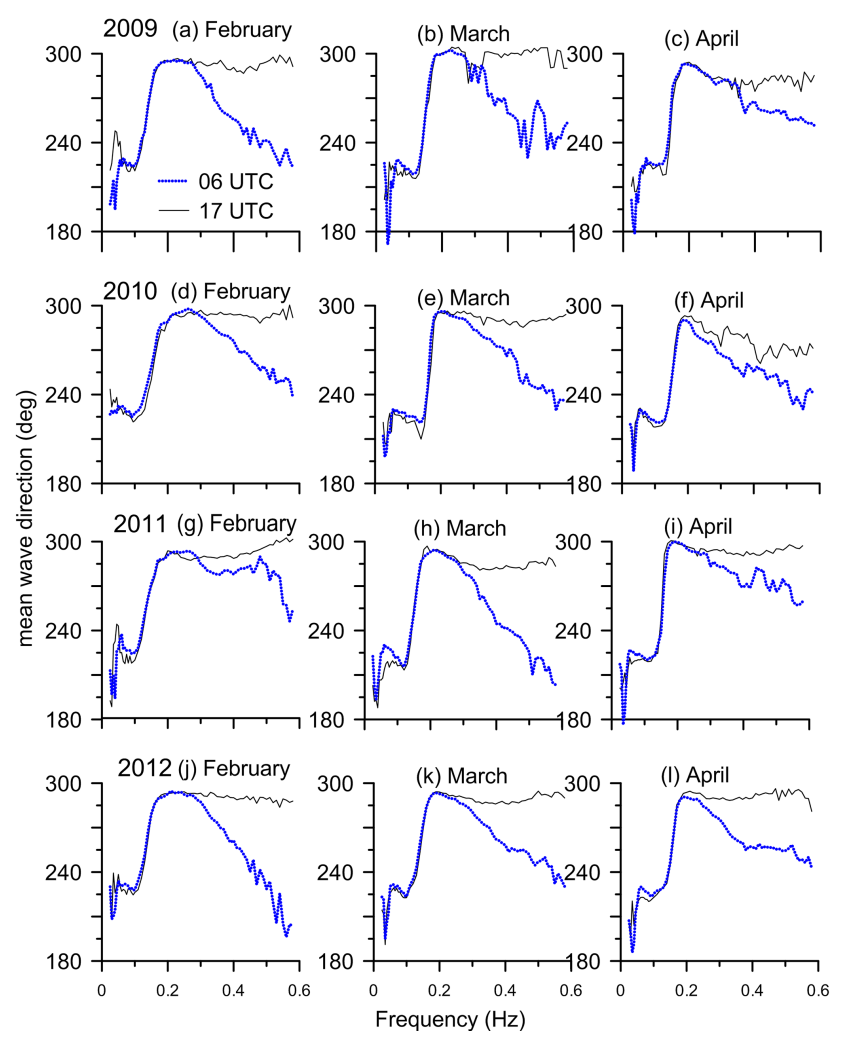

Figure 14. Monthly average mean wave direction during 06:00 and 17:00 UTC from February to April in (a-c) 2009, (d-f) 2010, (gi) 2011 and (j-l) 2012 .

Since measurement was carried out in relatively shallow locations (water depth $\sim 9 \mathrm{~m}$ ), the measured waves are influenced by the depth. The ratio of water depth and wave length associated with the mean wave period varied from 0.05 to 0.91 with an annual average value of 0.2 to $0.25(<0.5)$ for different years, indicating that the measured waves are in transitional water. Hence, the waves measured are transformed waves, and the wave height, wave direction and the wave spectra reported in this paper will be different from that in deep water. Kumar et al. (2014) reported that, depending on the wave period, waves from $210^{\circ}$ in deep water will have a direction of $217-241^{\circ}$ at $9 \mathrm{~m}$ water depth off Honnavar.

\section{Conclusions}

The variations in wave spectral characteristics during 20092012 are studied based on the measured wave data at $9 \mathrm{~m}$ water depth off the central west coast of India. Inter-annual variations in the wave spectrum are observed for all months with large variations during January-February, May and OctoberNovember. The annual average wave spectrum has higher peak energy during 2011 due to the higher spectral energy present during the monsoon period and the annual average maximum spectral energy density is high during 2011. 
The annual average spectrum of waves with significant wave height more than $2 \mathrm{~m}$ is similar in the four years with the peak frequency around $0.09 \mathrm{~Hz}$. Due to the sea breeze, an increase in the spectral energy of the wind-sea part is observed between 15:00 and 18:00 UTC during February-April. During the non-monsoon period, the high frequency part of the wave spectrum beyond $0.2 \mathrm{~Hz}$ is proportional to $f^{-3}$, whereas the decreasing of the high frequency part of the swell peak between 0.07 and $0.11 \mathrm{~Hz}$ is proportional to $f^{-4}$.

Acknowledgements. The Director, CSIR-NIO, Goa provided encouragement to carry out the study. The authors thank Mr. Jai Singh, technical assistant at CSIR-NIO, for help during data analysis. This work is part of the PhD Thesis of M. Anjali Nair. We thank the two anonymous reviewers for critical comments and suggestions which improved the presentation of the paper. This is NIO contribution No. 5699.

Topical Editor V. Kotroni thanks H. B. Branger and one anonymous referee for their help in evaluating this paper.

\section{References}

Aboobacker, V. M., Seemanth, M., Samiksha, S. V., Sudheesh, K., Jyoti, K., and Vethamony, P.: Sea breeze-induced wind sea growth in the central west coast of India, Ocean Eng., 84, 20-28, 2014.

Anoop, T. R., Kumar, V. S., and Shanas, P. R.: Spatial and temporal variation of surface waves in shallow waters along eastern Arabian Sea, Ocean Eng., 81, 150-157, doi:10.1016/j.oceaneng.2014.02.010, 2014.

Baba, M., Dattatri,, J., and Abraham, S.: Ocean wave spectra off Cochin, west coast of India, Indian J. Mar. Sci., 18, 106-112, 1989.

Caires, S. and Swail, V. R.: Global wave climate trend and variability analysis, paper presented at the 8th International Workshop on Wave hindcasting and Forecasting, U.S. Army Eng. Res. and Dev. Cent. Coastal and Hydraulics Lab., North Shore, Hawaii, 14-19 November, 2004.

Carter, D. J. T. and Draper, L.: Has the North East Atlantic become rougher?, Nature, 332, 494, doi:10.1038/332494a0, 1988.

Cuchiara, D. C., Fernandes, E. H., Strauch, J. C., Winterwerp, J. C., and Calliari, L. J.: Determination of the wave climate for the southern Brazilian shelf, Cont. Shelf Res., 29, 545-555, 2009.

Donelan, M. A., Hamilton, J., and Hui, W. H.: Directional spectra of wind generated waves, Philos. T. Roy. Soc. London, 315, 50962, 1985 .

Earle, M. D.: Development of algorithms for separation of sea and swell, Technical Report MEC-87-1, National Data Buoy Center, Stennis Space Center, MS, 53 pp., 1984.

Glejin, J., Kumar, V. S., Philip, C. S., Singh, J., Pednekar, P., Kumar, K. A., Dora, U. G., and Gowthaman, R.: Variations in swells along eastern Arabian Sea during the summer monsoon, Open J. Mar. Sci., 2, 43-50, 2012.

Glejin, J., Sanil Kumar, V., Balakrishnan Nair, T. M., and Singh, J.: Influence of winds on temporally varying short and long period gravity waves in the near shore regions of the eastern Arabian Sea, Ocean Sci., 9, 343-353, doi:10.5194/os-9-343-2013, 2013.
Goda, Y.: Analysis of wave grouping and spectra of long-travelled swell, Japan, Rep. Port Harbour Res. Inst., 22, 3-41, 1983.

Hanson, J. L. and Phillips, O. M.: Automated analysis of ocean surface directional wave spectra, J. Atmos. Ocean. Tech., 18, 277293, 2001.

Hasselmann, K., Barnett, T. P., Bouws, E., Carlson, H., Cartwright, D. E., Enke, K., Ewing, J. A., Gienapp, H., Hasselmann, D. E., Kruseman, P., Meerburg, A., Muller, P., Olbers, D. J., Richter, K., Sell, W., and Walden, H.: Measurements of wind-wave growth and swell decay during the Joint North Sea Wave Project (JONSWAP), Deutsche Hydrograph. Z., p. 95, 1973.

Kalnay, E., Kanamitsu, M., Kistler, R., Collins, W., Deaven, D., Gandin, L., Iredell, M., Saha, S., White, G., Woollen, J., Zhu, Y., Leetmaa, A., Reynolds, B., Chelliah, M., Ebisuzaki, W., Higgins, W., Janowiak, J., Mo, K. C., Ropelewski, C., Wang, J., Jenne, R., and Joseph, D.: The NCEP/NCAR 40-year reanalysis project, B. Am. Meteorol. Soc., 77, 437-471, 1996.

Kuik, A. J., Vledder, G., and Holthuijsen, L. H.: A method for the routine analysis of pitch and roll buoy wave data, J. Phys. Oceanogr., 18, 1020-1034, 1988.

Kumar, V. S. and Kumar, K. A.: Spectral representation of high shallow water waves, Ocean Eng., 35, 900-911, 2008.

Kumar, V. S., Kumar, K. A., and Anand, N. M.: Characteristics of waves off Goa, west coast of India, J. Coastal. Res., 16, 782-789, 2000.

Kumar, V. S., Anand, N. M., Kumar, K. A., and Mandal, S.: Multipeakedness and groupiness of shallow water waves along Indian coast, J. Coastal. Res., 19, 1052-1065, 2003.

Kumar, V. S., Johnson, G., Dora, G. U., Philip, S. C., Singh, J., and Pednekar, P.: Variations in nearshore waves along Karnataka, west coast of India, J. Earth. Syst. Sci., 121, 393-403, 2012.

Kumar, V. S., Shanas, P. R., and Dubhashi, K. K.: Shallow water wave spectral characteristics along the eastern Arabian Sea, Na. Hazards, 70, 377-394, doi:10.1007/s11069-013-0815-7, 2014.

Neetu, S., Shetye, S. R., and Chandramohan, P.: Impact of seabreeze on wind-seas off Goa, west coast of India, J. Earth Syst. Sci., 115, 229-234, 2006.

Pascal, R. W., Yelland, M. J., Srokosz, M. A., Moat, B. I., Waugh, E. M., Comben, D. H., Cansdale, A. G., Hartman, M. C., Coles, D. H., Hsueh, P. C., and Leighton, T. G.: A Spar Buoy for HighFrequency Wave Measurements and Detection of Wave Breaking in the Open Ocean, J. Atmos. Ocean. Tech., 28, 590-605, 2011.

Sajiv, P. C., Kumar, V. S., Glejin, J., Udhaba, D. G., and Vinayaraj, P.: Interannual and seasonal variations in nearshore wave characteristics off Honnavar, west coast of India, Curr. Sci., 103, 286292, 2012.

Shanas, P. R. and Sanil Kumar, V.: Temporal variations in the wind and wave climate at a location in the eastern Arabian Sea based on ERA-Interim reanalysis data, Nat. Hazards Earth Syst. Sci., 14, 1371-1381, doi:10.5194/nhess-14-1371-2014, 2014.

Soares, C. G.: On the occurrence of double peaked wave spectra, Ocean Eng., 18, 167-171, 1991.

USACE: Shore protection manual, Department of the Army, U.S. Corporations of Engineers, Washington DC, 2.58-2.59, 1984.

Vanem, E. and Walker, S. E.: Identifying trends in the ocean wave climate by time series analyses of significant wave height data, Ocean Eng., 61, 148-160, 2013. 
Vethamony, P., Aboobacker, V. M., Menon, H. B., AshokKumar, K., and Cavaleri, L.: Super imposition of wind season pre-existing swells off Goa coast, J. Mar. Syst., 87, 47-54, 2011.

Young, I. R. and Verhagen, L. A.: The growth of fetch limited waves in water of finite depth. Part I: Total energy and peak frequency, Coastal Eng., 29, 47-78, 1996.
Young, I. R., Zieger, S., and Babanin, A.: Global trends in wind speed and wave height, Science, 332, 451-455, 2011. 